\title{
Cocoa polyphenols and fiber modify colonic gene expression in rats
}

\author{
Malen Massot-Cladera ${ }^{1,2} \cdot$ Àngels Franch ${ }^{1,2} \cdot$ Margarida Castell ${ }^{1,2}$. \\ Francisco J. Pérez-Cano ${ }^{1,2}$
}

Received: 23 July 2015 / Accepted: 20 May 2016 / Published online: 2 June 2016

(C) The Author(s) 2016. This article is published with open access at Springerlink.com

\begin{abstract}
Purpose Cocoa intake has been associated with health benefits, improving cardiovascular function and metabolism, as well as modulating intestinal immune function. The aim of this study was to take an in-depth look into the mechanisms affected by the cocoa intake by evaluating the colonic gene expression after nutritional intervention, and to ascertain the role of the fiber of cocoa in these effects.

Methods To achieve this, Wistar rats were fed for 3 weeks with either a reference diet, a diet containing $10 \%$ cocoa (C10), a diet based on cocoa fiber (CF) or a diet containing inulin (I). At the end of the study, colon was excised to obtain the RNA to evaluate the differential gene expression by microarray. Results were validated by RT-PCR.

Results The $\mathrm{C} 10$ group was the group with most changes in colonic gene expression, most of them down-regulated but a few in common with the CF diet. The C10 diet significantly up-regulated the expression of Scgblal and Scnnl $g$ and down-regulated Tac4, Mcpt2, Fcerla and Fabpl by twofold, most of them related to lipid metabolism and immune function. The $\mathrm{CF}$ and I diets down-regulated the expression of Serpina10 and Apoa4 by twofold. Similar patterns of expression were found by PCR.
\end{abstract}

Electronic supplementary material The online version of this article (doi:10.1007/s00394-016-1230-0) contains supplementary material, which is available to authorized users.

Francisco J. Pérez-Cano

franciscoperez@ub.edu

1 Department of Physiology, Faculty of Pharmacy, University of Barcelona, Av Joan XXIII s/n, Edifici B, 3a planta, 08028 Barcelona, Spain

2 Nutrition and Food Safety Research Institute (INSA), University of Barcelona, Prat de la Riba, 171, Santa Coloma de Gramenet 08921, Spain
Conclusion Most of the effects attributed to cocoa consumption on genes related to the immune system (B cell and mast cell functionality) and lipid metabolism in the colon tissue were due not only to its fiber content, but also to the possible contribution of polyphenols and other compounds.

Keywords Cocoa $\cdot$ Colonic gene expression · Dietary fiber $\cdot$ Immune function $\cdot$ Lipid metabolism

\section{Introduction}

The increasing interest in finding food-based strategies with health-improving effects has turned cocoa, the fruit of the cocoa tree (Theobroma cacao L.), into one of the subject matters of study. The health benefits provided by cocoa consumption in the prevention of diseases and physiological disorders have been described. Thus, cocoa consumption has long been demonstrated to improve cardiovascular status, decreasing blood pressure and reducing platelet aggregation [1, 2]. In addition, cocoa intake has been shown to increase HDL cholesterol, to protect against LDL oxidation and to improve hyperlipidemia, insulin sensitivity and hyperglycemia [3, 4], and there is emerging evidence of the beneficial role of chocolate in reducing body weight/body fat $[5,6]$. In addition, studies concerning the cocoa protector effect against carcinogenesis [7], neurodegenerative diseases and cognitive function [8] have also been published.

Preclinical studies have demonstrated that cocoa exerts immune modulation in both systemic and intestinal compartments [9]. In this context, immunoglobulin production is modulated after cocoa intake and, in consequence, cocoa has been tested as a possible adjuvant treatment in allergic reactions [10]. In addition, the intake of cocoa affects the 
intestinal compartment by modulating the microbiota, as assessed in vivo and clinical studies [11] and also the Tolllike receptor (TLR) expression, key molecules involved in the recognition of microorganisms and inductors of inflammatory response [12] both in the inductive and effectors intestinal immune tissues, where antigens are sampled lymphocytes are activated and where the effector cells contribute to the formation of S-IgA antibodies, respectively [13-15].

Whatever the cocoa effect, most of these beneficial actions of cocoa have been attributed to its high content of polyphenols, mainly flavonoids such as (-)-epicatechin, $(+)$-catechin and their polymeric forms called procyanidins [16]. Thus, flavonoids have been related to cocoa-induced cardiovascular effects $[1,2]$, protection against carcinogenesis [7], and cognitive function [8]. Nevertheless, it must be added that cocoa, besides being a strong source of flavonoids, also has a high content of dietary fiber (26-40 \%, mostly insoluble fiber) which could strengthen or be in part responsible for the effects described above. In general, dietary fiber appears to be particularly beneficial against various Western diseases, including metabolic syndrome [17] and, in particular, cocoa fiber, can prevent obesity by reducing body weight and improving glucose levels as well as controlling the blood lipid profile and lipid peroxidation in animals and human interventions [18].

One of the several possible mechanisms involved in the body weight control might be through the cocoa fiber's capacity to increase fat elimination in feces $[19,20]$ by binding bile acids and dietary fats, and interfering with lipid absorption in the small intestine [21, 22]. In addition, the effects of cocoa fiber assisting in the control of arterial blood pressure in hypercholesterolemic subjects have been reviewed [20]. Protection against disorders related to the gastrointestinal tract (i.e., constipation, irritable bowel syndrome) or colorectal and other types of cancer has also been attributed to cocoa fiber fermentation by the colonic microbiota which leads to the formation of short chain fatty acids (SCFA) [23].

Taking the above evidences together, the influence of cocoa consumption on the systemic and intestinal compartments is clear. These effects can be attributed to both its polyphenols and fiber content which can reach the colon, but also to their microbial metabolites produced after cocoa consumption. Therefore, we hypothesize that important events after cocoa intake are produced in the colon environment, where bioactive compounds of cocoa would interfere then in the gene expression of colon cells. The objective of the present work was to study in-depth the mechanisms involved in the beneficial effects of cocoa, mainly focused on immune system and lipid metabolism modulation, by evaluating changes in colonic gene expression after a preclinical nutritional intervention, and to ascertain whether cocoa fiber is responsible for these effects. For this purpose, the technique chosen is microarray analysis due to the fact that it is a powerful tool that allows global analysis of the expression of thousands of genes to be performed in a single assay [24].

\section{Materials and methods}

\section{Animals and diets}

Female Wistar rats ( 3 weeks old) were obtained from Janvier (Saint-Berthevin, France) and housed in cages under conditions of controlled temperature and humidity in a 12:12 light-dark cycle. The rats were randomly distributed into four dietary groups $(n=10 /$ each). The reference group (REF) was fed with a standard diet AIN-93 M (Harlan, Barcelona, Spain); the cocoa group (C10) was fed with a diet containing $0.4 \%$ of polyphenols, $0.85 \%$ of soluble fiber and $2.55 \%$ of insoluble fiber provided by $10 \%$ cocoa; the cocoa fiber group (CF) received a diet with the same cocoa soluble and insoluble fiber proportion as the $\mathrm{C} 10$ group but with a very low amount of polyphenols $(<0.02 \%)$; and a fourth group (I) received the same amount of soluble fiber as the $\mathrm{C} 10$ group $(0.85 \%)$ but in the form of inulin in order to distinguish the particular effect of cocoa fiber (Table 1). Natural Forastero cocoa and cocoa fiber powders [Idilia Foods SL (formerly Nutrexpa SL), Barcelona, Spain] with 4.02 and $0.35 \%$ of polyphenols, respectively, were used to elaborate the $\mathrm{C} 10$ and CF diets. Inulin from chicory roots (Fibruline ${ }^{\circledR}$ Instant; InnovaFood 2005, S.L, Barcelona, Spain) was used as a reference soluble fiber. The three experimental diets were elaborated from AIN-93 M formula by subtracting the amount of carbohydrates, proteins, lipids and insoluble fibers provided by the corresponding cocoa or cocoa fiber extracts. The resulting chows were isoenergetic and had the same proportion of macronutrients (carbohydrates, proteins and lipids) and insoluble fiber as the reference diet (Table 1).

Animals were given free access to water and chow. The diets lasted for 3 weeks. Studies were performed according to the criteria outlined by the Guide for the Care and Use of Laboratory Animals. Experimental procedures were reviewed and approved by the Ethical Committee for Animal Experimentation of the University of Barcelona (ref. 358/12).

\section{Sample collection and preparation}

At the end of the 3-week nutritional intervention, the rats were anesthetized intramuscularly with ketamine $(90 \mathrm{mg} /$ $\mathrm{kg}$ ) (Merial Laboratorios, S.A., Barcelona, Spain) and xylazine $(10 \mathrm{mg} / \mathrm{kg}$ ) (Bayer A.G, Leverkusen, Germany). A 5 -mm piece of the middle of the colon was collected from 
Table 1 Composition of nutrients and polyphenols provided by the three experimental diets $(\mathrm{g} / \mathrm{kg}$ diet $)$

\begin{tabular}{|c|c|c|c|c|}
\hline Components & REF (g/kg) AIN-93 M & $\mathrm{C} 10(\mathrm{~g} / \mathrm{kg})$ & $\mathrm{CF}(\mathrm{g} / \mathrm{kg})$ & $\mathrm{I}(\mathrm{g} / \mathrm{kg})$ \\
\hline Casein & 121.5 & 97.1 & 109.7 & 118.7 \\
\hline L-Cystine & 1.8 & 1.4 & 1.4 & 1.6 \\
\hline Corn starch & 418.1 & 423.7 & 437.2 & 426.4 \\
\hline Maltodextrin & 148.5 & 118.7 & 120.4 & 131.5 \\
\hline Sucrose & 102.6 & 108.7 & 110.9 & 110.9 \\
\hline Soybean oil & 38.2 & 26.2 & 33.5 & 38.9 \\
\hline Cellulose & 50 & 24.5 & 26.5 & 50.0 \\
\hline Minerals & 35.3 & 27.7 & 27.9 & 31.3 \\
\hline Vitamins & 9.1 & 7.2 & 7.2 & 8.1 \\
\hline Choline bitartrate & 2.5 & 2.0 & 2.0 & 2.2 \\
\hline tert-Butylhydroquinone & 0.008 & 0.006 & 0.006 & 0.006 \\
\hline Water & 72.4 & 63 & 71.1 & 72 \\
\hline Cocoa powder & - & 100 & - & - \\
\hline Protein & - & 22 & - & - \\
\hline Carbohydrate & - & 16 & - & - \\
\hline Lipid & - & 11 & - & - \\
\hline Fiber (insoluble/soluble) & - & $34(25.5 / 8.5)$ & - & - \\
\hline Minerals & - & 6 & - & - \\
\hline Total polyphenols ${ }^{1}$ & - & 4 & - & - \\
\hline Water & - & 7 & - & - \\
\hline Cocoa fiber powder & - & - & 52.3 & - \\
\hline Protein & - & - & 8 & - \\
\hline Carbohydrate & - & - & 0.5 & - \\
\hline Lipid & - & - & 4.8 & - \\
\hline Fiber (insoluble/soluble) & - & - & $31.9(23.4 / 8.5)$ & - \\
\hline Minerals & - & - & 7 & - \\
\hline Total polyphenols ${ }^{1}$ & - & - & 0.2 & - \\
\hline Water & - & - & - & - \\
\hline Inulin powder & - & - & - & 8.5 \\
\hline Protein & - & - & - & - \\
\hline Carbohydrate & - & - & - & - \\
\hline Lipid & - & - & - & - \\
\hline Fiber (insoluble/soluble) & - & - & - & $8.5(-/ 8.5)$ \\
\hline Minerals & - & - & - & - \\
\hline Total polyphenols ${ }^{1}$ & - & - & - & - \\
\hline Water & - & - & - & - \\
\hline
\end{tabular}

1 Total polyphenol compounds were quantified by Folin-Ciocalteu method all animals in aseptic conditions in RNAlater ${ }^{\circledR}$ and kept at $4{ }^{\circ} \mathrm{C}$ overnight before storing at $-20{ }^{\circ} \mathrm{C}$ for further gene expression analysis by microarray.

\section{RNA extraction}

For RNA isolation, tissue samples were transferred into lysing matrix tubes (MP Biomedicals, Illkirch, France) containing an appropriate buffer and were homogenized in a FastPrep ${ }^{\circledR}$ instrument (MP Biomedicals) for $30 \mathrm{~s}$. Lysates were centrifuged for $3 \mathrm{~min}$ at $12,000 \mathrm{~g}$ to eliminate excess tissue debris. The RNA was isolated by the RNeasy Mini Kit (Qiagen, Madrid, Spain) following the manufacturer's recommendations and then quantified with a NanoDrop spectrophotometer and NanoDrop IVD-1000 v.3.1.2 software (NanoDrop Technologies, Wilmington, DE, USA). The Agilent 2100 Bioanalyzer with the RNA 6000 LabChip kit (Agilent Technologies, Madrid, Spain) was used to provide an RNA integrity number for each sample. All samples used for further experiments showed an RNA integrity number $(\mathrm{RIN}) \geq 9$ and purity between 1.885 and 2.042 using the $\mathrm{A}_{260} / \mathrm{A}_{280}$ ratio. 


\section{Microarray procedure}

The study of the differential expression profiling was carried out with a SurePrint-G3 Rat GE $8 \times 60 \mathrm{~K}$ microarray kit (ID 028279, Agilent Technologies, Madrid, Spain), following a loop experimental design in which a pairwise comparison was done. Quadruplicate samples for each experimental condition were employed, and dye swaps (Cy3 and Cy5) were performed to the RNA amplified from each sample. RNA quality was assessed using a TapeStation (Agilent Technologies). RNA concentration and dye incorporation were measured using a UV-Vis spectrophotometer (Nanodrop 1000, Agilent Technologies, Wilmington, DE, USA). Labeling and hybridization to microarray were conducted following the manufacturer's two-color protocol (Two-Color Microarray-Based Gene Expression Analysis v. 6.5, Agilent Technologies), using LowInput QuickAmp Labeling Kit and Agilent Microarray Hybridization Chamber Kit for labeling and hybridization, respectively. Microarray chips were then washed and immediately scanned using a DNA Microarray Scanner (Model G2505C, Agilent Technologies) by the Genetic Diagnostic Bioarray facilities (Bioarray, Alicante, Spain).

\section{Microarray data analysis}

Data extraction was performed with Agilent Feature Extraction Software v.10.7 (Agilent Technologies). Bioinformatic analysis was performed with Bioconductor software under $\mathrm{R}$ environment, using the following packages: limma (v.3.16.1) for background correction and normalization, Marray and pcaMethods for quality control plots, RankProd for differential expression and finally GOstats (v.2.26.0.) and GSEABase for gene ontology functional analysis. Latest gene annotations available were used. Raw feature intensities were background-corrected using normexp background correction algorithm. Within-array normalization was done using spatial and intensity-dependent loess. Aquantile normalization was used to normalize between arrays. The expression of each gene is reported as the base 2 logarithm of ratio of the value obtained of each condition relative to control condition (REF group). A gene is considered differentially expressed if it displays a PFP (percentage of false prediction, equivalent of false discovery rate, FDR) less than 0.05 by rank product nonparametric method (RankProd). Venn diagrams in GX allowed finding differently expressed genes that followed the same pattern (e.g., up-regulated or down-regulated) in common among the experimental conditions. Finally, up- and downregulated genes were analyzed in terms of gene ontology by using a hypergeometric analysis (GOStats). The output of this analysis was then filtered using two different criteria. On the one hand, data were filtered by fold expression, generating lists of differentially expressed genes by at least twofold, whereas on the other hand, data were filtered taking into account the statistical significance of the enrichment analysis for the over and under represented GO terms belonging to the biological process (BP), cellular component (CC) and molecular function (MF) domains. The microarray data have been lodged in the Gene Expression Omnibus (http://www.ncbi.nlm.nih.gov/geo/) as accession number: GSE7095.

\section{Gene function analysis}

Gene ontology annotation of broad terms belonging to the BP domain was performed using ClueGO v2.2.4 and Clupedia v1.2.4, a Cytoscape plugins [25, 26]. Briefly, gene symbols from both up- and down-regulated genes (Tables 2, 3, respectively) were uploaded and analyzed with the following default parameters: enrichment (rightsided hypergeometric test) correction method using Bonferroni step down analysis mode and showing only the pathways with $\mathrm{pV} \leq 0.05$; "Function" load a gene cluster list for Rattus norvegicus; view style setting set to "Cluster"; evidenced codes set to "All"; networking specificity set to "medium" (GO levels 3-8); advanced term/pathway selection option set to 3 for the minimum genes and $4 \%$ of genes for both clusters; and Kappa score threshold set to 0.3. A network was constructed for each pairwise comparison (C10 vs REF; CF vs REF and I vs REF; 3 networks in total). These networks provide a global view of potentially relevant, interacting partners of genes with abundant changes.

\section{Validation of gene expression by real-time PCR}

Two micrograms of total RNA was converted to cDNA. Specific PCR TaqMan ${ }^{\circledR}$ primers and probes (Applied Biosystems, AB, Weiterstadt, Germany) were used to measure selected targets: Scgblal (Rn00564903_m1, inventoried (I)), Scnnl $g$ (Rn00566891_m1, I), Fabpl (Rn00664587_m1，I), Serpinal0 (Rn00592428_m1，I), Mcpt2 (Rn00756479_g1, I), Fcerla (Rn00562369_m1, I), Apoa4 (Rn00562482_m1, I) and Tac4 (Rn00597278_m1, I). Quantitative real-time PCR assays were performed in duplicate for each sample using an ABI PRISM 7900HT Sequence Detection System (AB). Quantification of the genes being studied was normalized to the housekeeping genes Gusb (Rn00566655_m1, I). The SDS v2.4 software $(\mathrm{AB})$ was used to analyze the expression data. Results are expressed as the fold change of the amount of target mRNA relative to the endogenous control expression calculated using the standard $2^{-\Delta \Delta C t}$ method for the three experimental groups relative to values from the REF group, which represents a onefold change in gene expression. 
Table 2 List of up-regulated genes differentially expressed by $\geq$ twofold with a $P<0.05$ obtained after the $10 \%$ cocoa diet intake (C10 group) compared to the REF group ( $n=4$ /group)

\begin{tabular}{|c|c|c|c|}
\hline Symbol & $\begin{array}{l}\mathrm{C} 10 \text { vs REF } \\
\log 2 \mathrm{FC}\end{array}$ & $\begin{array}{l}\mathrm{CF} v s \mathrm{REF} \\
\log 2 \mathrm{FC}\end{array}$ & $\begin{array}{l}\text { I vs REF } \\
\log 2 \mathrm{FC}\end{array}$ \\
\hline Scgblal & 3.948 & 1.716 & 1.139 \\
\hline Scnn1g & 3.119 & 1.133 & 0.573 \\
\hline Fxyd4 & 2.583 & 2.089 & 0.718 \\
\hline Slc15a1 & 2.332 & 1.388 & 0.475 \\
\hline Gbpl & 2.207 & 1.662 & 0.432 \\
\hline Cyp $2 f 4$ & 2.185 & 1.436 & 0.367 \\
\hline Dpysl4 & 2.069 & 1.387 & 0.242 \\
\hline Fmo2 & 2.040 & 1.007 & 0.426 \\
\hline Pdyn & 1.873 & 0.194 & 0.175 \\
\hline$M t 2 A$ & 1.656 & 0.644 & -0.147 \\
\hline$R G D 1561239$ & 1.597 & 1.787 & 0.742 \\
\hline Sftpd & 1.583 & 0.163 & 0.351 \\
\hline Mme & 1.580 & 0.636 & 0.353 \\
\hline Hoxd13 & 1.575 & 0.615 & 0.100 \\
\hline Chst5 & 1.533 & 0.591 & 0.082 \\
\hline Atp12a & 1.457 & 1.630 & 0.500 \\
\hline Thbs4 & 1.450 & 0.908 & 0.302 \\
\hline Hoxd10 & 1.403 & 0.668 & 0.164 \\
\hline Trpv1 & 1.390 & 0.749 & 0.058 \\
\hline Hoxb13 & 1.358 & 0.786 & 0.101 \\
\hline Spink3 & 1.338 & 1.162 & 0.463 \\
\hline LOC687303 & 1.327 & 0.734 & 0.755 \\
\hline Abat & 1.319 & 1.272 & 0.477 \\
\hline Angptl4 & 1.316 & 0.914 & 0.670 \\
\hline Aox4 & 1.311 & 0.054 & 0.320 \\
\hline B3gnt7 & 1.265 & 0.403 & 0.019 \\
\hline $\operatorname{Pcsk} 9$ & 1.253 & 0.048 & 0.063 \\
\hline$R G D 1560608$ & 1.225 & 0.759 & 0.709 \\
\hline Guca2b & 1.211 & 0.811 & 0.287 \\
\hline Padi3 & 1.190 & 0.832 & 0.462 \\
\hline Scnnlb & 1.181 & 0.499 & 0.057 \\
\hline$L O C 287167$ & 1.178 & 0.607 & 0.296 \\
\hline RGD1308274 & 1.142 & 0.073 & 0.321 \\
\hline$S m c 1 b$ & 1.133 & 0.968 & 0.031 \\
\hline$P d e 7 a$ & 1.129 & 0.708 & 0.405 \\
\hline LOC100363350 & 1.126 & 0.621 & 0.446 \\
\hline Gsta2 & 1.111 & 0.537 & 0.157 \\
\hline Slc20al & 1.110 & 0.624 & 0.056 \\
\hline$R G D 1310110$ & 1.097 & 0.410 & 0.231 \\
\hline LOC689064 & 1.095 & 1.024 & 0.501 \\
\hline Rnase1 & 1.094 & 1.063 & 1.218 \\
\hline Dnase1 & 1.088 & 1.087 & 0.124 \\
\hline $\operatorname{siat} 7 D$ & 1.058 & 0.363 & 0.096 \\
\hline Serpincl & 1.053 & 0.873 & 0.469 \\
\hline LOC494499 & 1.029 & 0.576 & 0.276 \\
\hline Fbxl13 & 1.028 & 1.009 & 0.067 \\
\hline
\end{tabular}

Table 2 continued

\begin{tabular}{lllr}
\hline Symbol & C10 vs REF & CF vs REF & I vs REF \\
& $\log 2 \mathrm{FC}$ & $\log 2 \mathrm{FC}$ & $\log 2 \mathrm{FC}$ \\
\hline Alox15 & 1.028 & 0.387 & $\mathbf{0 . 1 9 1}$ \\
Creg1 & 1.021 & 0.406 & $\mathbf{- 0 . 0 0 8}$ \\
Rnase1l2 & 1.010 & 0.857 & $\mathbf{1 . 0 1 2}$ \\
Alas2 & 1.007 & 0.997 & 0.452 \\
\hline
\end{tabular}

This includes the gene symbol for all the up-regulated genes. Values are expressed as a $\log 2$ of fold change and shown when $\geq 1$. Values for the two other experimental diets are also included, although independently of their fold change and/or their significance. Values in bold and cursive represent the non-statistically significant changes

\section{Statistics}

Statistical analysis of PCR results was performed using the software package SPSS 22.0 (SPSS, Inc.). Levene's and Kolmogorov-Smirnov tests were applied to assess variance equality and normal distribution, respectively. Nonparametric tests were performed when normal distribution and equality of variance did not exist. Specifically, KruskalWallis and Mann-Whitney $U$ tests were used in order to assess significance for independent samples. Significant differences were established at $P<0.05$.

\section{Results \\ Body weight and chow intake}

Body weight and chow intake were monitored throughout the study. The initial body weight was similar among the groups $(44.4 \pm 0.7 \mathrm{~g})$ increasing during the study up to $154.8 \mathrm{~g}$ in the REF group. In animals fed $10 \%$ cocoa diet, body weight increase was lower than that in the other groups, the difference already being significant at day 7 , and, at the end, the body weight was $\sim 35 \mathrm{~g}$ less than that in the rest of the groups $(P<0.05)$. This effect, also observed in previous studies $[13,14,27]$, was not related to a lower chow intake since this was similar in all the experimental groups (data not shown) throughout the study as well as in reported studies [13, 14, 27]. No changes in body weight were found due to the $\mathrm{CF}$ or I diets.

\section{Colon gene expression profiles and commonly modulated genes}

Three weeks of diet containing either $10 \%$ cocoa, the equivalent amount of cocoa fiber or the equivalent amount of inulin as soluble fiber, produced changes in the gene expression of colon. The $\mathrm{C} 10$ group produced more changes than the $\mathrm{CF}$ and I groups, with most of these 
Table 3 List of down-regulated genes differentially expressed by $\geq$ twofold with a $P<0.05$ obtained after the $10 \%$ cocoa diet intake $($ C10 group) compared to the REF group ( $n=4 /$ group)

\begin{tabular}{|c|c|c|c|c|c|c|c|}
\hline Symbol & $\begin{array}{l}\mathrm{C} 10 \text { vs REF } \\
\log 2 \mathrm{FC}\end{array}$ & $\begin{array}{l}\mathrm{CF} v s \mathrm{REF} \\
\log 2 \mathrm{FC}\end{array}$ & $\begin{array}{l}\text { I vs REF } \\
\log 2 \mathrm{FC}\end{array}$ & Symbol & $\begin{array}{l}\mathrm{C} 10 \text { vs REF } \\
\log 2 \mathrm{FC}\end{array}$ & $\begin{array}{l}\mathrm{CF} v s \mathrm{REF} \\
\log 2 \mathrm{FC}\end{array}$ & $\begin{array}{l}\text { I vs REF } \\
\log 2 \mathrm{FC}\end{array}$ \\
\hline Syce 2 & -1.000 & -1.117 & 0.028 & Olfm4 & -1.291 & -0.826 & 0.002 \\
\hline Chga & -1.011 & -0.328 & -0.133 & $M t 3$ & -1.298 & -0.631 & -0.372 \\
\hline Smpx & -1.016 & -0.349 & -0.381 & Casq2 & -1.298 & -0.643 & -0.218 \\
\hline Myl2 & -1.019 & -0.940 & -0.823 & $H s d 3 b 5$ & -1.302 & -0.648 & -0.340 \\
\hline Ptgis & -1.026 & -0.370 & -0.173 & Gsta5 & -1.308 & -0.560 & -0.158 \\
\hline$C f d$ & -1.037 & -0.087 & 0.009 & $P \ln$ & -1.309 & -0.384 & -0.349 \\
\hline Msln & -1.041 & 0.382 & 0.377 & Nox 1 & -1.313 & -0.256 & 0.207 \\
\hline LOC 360228 & -1.041 & 0.559 & 0.231 & Mel & -1.324 & -0.443 & -0.264 \\
\hline Kcnj5 & -1.043 & -1.062 & -0.766 & Casc4 & -1.334 & -0.688 & -0.715 \\
\hline Car3 & -1.045 & 0.278 & -0.263 & LOC682360 & -1.335 & -0.459 & -0.314 \\
\hline Slpil2 & -1.050 & 0.102 & 0.425 & $\operatorname{Sln}$ & -1.360 & -0.649 & -0.410 \\
\hline $\mathrm{Ca} 2$ & -1.055 & -0.551 & -0.087 & $R G D 1563231$ & -1.370 & -0.170 & -0.580 \\
\hline $\operatorname{Rgs} 2$ & -1.059 & -0.856 & -0.760 & Slpi & -1.378 & 0.188 & 0.552 \\
\hline$M f_{s} d 2 a$ & -1.059 & -0.455 & -0.262 & $R G D 1562127$ & -1.382 & -0.687 & -0.360 \\
\hline Tnfrsf $12 a$ & -1.059 & -0.600 & -1.353 & Sgcg & -1.386 & -0.884 & -0.543 \\
\hline Car8 & -1.060 & -0.525 & -0.339 & LOC685106 & -1.390 & 0.215 & -0.613 \\
\hline Mybpc 2 & -1.064 & -0.459 & -0.353 & $H d c$ & -1.393 & -0.281 & -0.076 \\
\hline Gcnt3 & -1.071 & -0.549 & -0.183 & Retnlb & -1.420 & 1.223 & 1.939 \\
\hline Mrap & -1.072 & -0.045 & -0.363 & $R G D 1565374$ & -1.430 & -0.901 & -0.378 \\
\hline Tmprss 9 & -1.077 & -1.024 & -0.582 & Apobec 2 & -1.436 & -0.613 & -0.243 \\
\hline Gldn & -1.085 & -0.522 & -0.161 & Sypl2 & -1.457 & -0.801 & -0.867 \\
\hline$H s d 3 b 6$ & -1.086 & -0.518 & -0.228 & Fcerla & -1.497 & -0.248 & -0.283 \\
\hline Casql & -1.086 & -0.436 & -0.282 & Hsd17b6 & -1.503 & -0.988 & -0.325 \\
\hline$R G D 1560314$ & -1.089 & -0.959 & -0.119 & $R G D 1565970$ & -1.509 & -0.198 & 0.413 \\
\hline$R G D 1309651$ & -1.094 & -0.426 & -0.103 & Tph1 & -1.518 & -0.642 & -0.305 \\
\hline Ly49i2 & -1.102 & -0.604 & -1.177 & $C f b$ & -1.551 & 0.167 & 0.560 \\
\hline LOC 363060 & -1.108 & -0.829 & -0.616 & Slfn3 & -1.558 & 0.166 & 0.249 \\
\hline LOC688635 & -1.113 & -0.189 & -0.038 & Retnlg & -1.560 & -0.018 & 0.509 \\
\hline Kiflc & -1.125 & -0.943 & -0.701 & LOC679045 & -1.562 & -0.216 & -0.234 \\
\hline LOC687842 & -1.126 & -0.830 & -0.489 & Cmal & -1.583 & -0.288 & 0.256 \\
\hline Scx & -1.131 & -0.368 & -0.413 & Сра3 & -1.609 & -0.258 & -0.115 \\
\hline Slc13al & -1.134 & -0.585 & -0.301 & Retnla & -1.627 & 0.878 & 1.162 \\
\hline Ccr10 & -1.137 & 0.036 & 0.419 & Сур $4 f 1$ & -1.634 & -0.582 & 0.169 \\
\hline$M z b l$ & -1.140 & 0.064 & 0.772 & Npc1ll & -1.662 & -1.294 & -0.707 \\
\hline$M s 4 a 2$ & -1.144 & -0.127 & 0.012 & $T f f 1$ & -1.663 & -0.786 & -0.310 \\
\hline Rup2 & -1.145 & -1.201 & -0.220 & Atf3 & -1.681 & -1.015 & -1.715 \\
\hline Rrad & -1.150 & -0.320 & -0.193 & Fabpl & -1.682 & -0.780 & -0.074 \\
\hline$F b \ln 7$ & -1.156 & -0.540 & -0.398 & Tnfrsf17 & -1.690 & -0.139 & 0.572 \\
\hline Bpifb6 & -1.156 & -0.825 & -0.560 & Spink4 & -1.714 & -2.376 & -1.237 \\
\hline$C d 55$ & -1.162 & -0.438 & -0.237 & LOC100360169 & -1.718 & 0.232 & 1.101 \\
\hline$F 2$ & -1.165 & -0.640 & -0.315 & Ros1 & -1.733 & -1.914 & -1.672 \\
\hline Fabp4 & -1.170 & -0.233 & -0.334 & Thrsp & -1.747 & -0.067 & -0.380 \\
\hline Myom 2 & -1.171 & -0.772 & -0.257 & RatNP $-3 b$ & -1.761 & -2.005 & -0.576 \\
\hline RGD1305928 & -1.180 & -0.851 & -0.388 & $R G D 1564563$ & -1.793 & -0.383 & -0.092 \\
\hline Slc18a1 & -1.184 & -0.791 & -0.599 & Mcpt8 & -1.824 & -0.324 & 0.315 \\
\hline $\operatorname{Rgsl}$ & -1.184 & -0.675 & -0.604 & Mcpt8l3 & -1.824 & -0.462 & 0.151 \\
\hline Dapl1 & -1.196 & -0.753 & -0.375 & Adipoq & -1.826 & 0.053 & -0.265 \\
\hline
\end{tabular}


Table 3 continued

\begin{tabular}{|c|c|c|c|c|c|c|c|}
\hline Symbol & $\begin{array}{l}\text { C10 vs REF } \\
\log 2 \mathrm{FC}\end{array}$ & $\begin{array}{l}\text { CF } v s \mathrm{REF} \\
\log 2 \mathrm{FC}\end{array}$ & $\begin{array}{l}\text { I vs REF } \\
\log 2 \mathrm{FC}\end{array}$ & Symbol & $\begin{array}{l}\mathrm{C} 10 \text { vs REF } \\
\log 2 \mathrm{FC}\end{array}$ & $\begin{array}{l}\text { CF vs REF } \\
\log 2 \mathrm{FC}\end{array}$ & $\begin{array}{l}\text { I vs REF } \\
\log 2 \mathrm{FC}\end{array}$ \\
\hline Tmem22 & -1.199 & -0.583 & -0.419 & Mcpt9 & -1.834 & -0.384 & 0.240 \\
\hline Ccl12 & -1.212 & 0.206 & 0.243 & Mcpt4 & -1.952 & 0.233 & 0.296 \\
\hline Siglec1 & -1.213 & 0.130 & 0.102 & Mcpt1 & -1.966 & -0.014 & 0.285 \\
\hline Fcgr3a & -1.230 & -0.225 & 0.136 & Mcpt10 & -1.985 & -0.523 & 0.192 \\
\hline LOC686141 & -1.230 & -0.200 & 0.140 & LOC100359793 & -1.987 & -0.141 & 1.137 \\
\hline LOC683753 & -1.232 & -0.795 & -0.121 & Scdl & -1.998 & 0.138 & -0.400 \\
\hline Bhlha15 & -1.233 & -0.496 & -0.067 & Mcpt 812 & -2.003 & -0.532 & 0.196 \\
\hline LOC688507 & -1.238 & -0.184 & 0.110 & Pga5 & -2.086 & -1.394 & -0.775 \\
\hline$H 19$ & -1.242 & -0.227 & -0.317 & Gkn2 & -2.099 & -1.000 & -1.584 \\
\hline Cxcl11 & -1.260 & -0.859 & -0.267 & Mcpt1l4 & -2.170 & -0.112 & 0.239 \\
\hline $\operatorname{Rgs} 4$ & -1.262 & -0.570 & -0.720 & $R G D 1562035$ & -2.179 & -0.248 & 0.176 \\
\hline Ces $2 c$ & -1.269 & -0.944 & -0.445 & $P z p$ & -2.223 & -1.221 & -1.117 \\
\hline Fut 9 & -1.270 & -0.997 & -0.334 & Fcrls & -2.342 & -0.529 & 0.208 \\
\hline Srpk3 & -1.272 & -0.242 & -0.042 & Bpifb2 & -2.508 & -1.532 & -1.300 \\
\hline$R G D 1560949$ & -1.273 & -1.471 & -1.135 & Mcpt2 & -2.545 & -0.290 & 0.255 \\
\hline$N p w$ & -1.276 & -0.777 & -0.406 & Tac4 & -2.766 & -1.731 & -1.279 \\
\hline$R b p 4$ & -1.283 & -0.026 & -0.205 & & & & \\
\hline
\end{tabular}

This includes the gene symbol for all the down-regulated genes. Values are expressed as a $\log 2$ of fold change and shown when $\leq-1$. Values for the two others experimental diets are also included, although independently of their fold change and/or their significance. Values in bold and cursive represent the non-statistically significant changes

changes being down-regulated and only a few of them in common with the CF diet. Likewise, very few similarities were detected between the $\mathrm{CF}$ and I diets, the I group being the one with the fewest changes.

To show the number of genes affected in common, a Venn diagram representation was drawn comparing separately the list of significantly up- and down-modified genes $(P<0.05)$ obtained for the three experimental diet groups of animals compared to the REF group (Fig. 1). The C10 and $\mathrm{CF}$ groups shared a total of 79 modulated genes, 31 of which were up-regulated and 48 down-regulated. The CF and I groups were found to have a total of 28 modulated genes in common, of which 8 were up-regulated and 20 down-regulated. Finally, a total of 18 modulated genes-3 up-regulated and 15 down-regulated-were shared between the $\mathrm{C} 10$ and I groups. The expression of 14 genes was found to have been modified in common by the three experimental diets ( 3 up- and 11 down-regulated).

Focusing on the uncommon modulated genes (Fig. 1), the cocoa-fed animals showed the highest modulation for both up- and down-regulations (64 and 175, respectively), whereas both the cocoa fiber and inulin diets modulated a similar number of different genes, with the number of upand down-regulated genes also being similar.

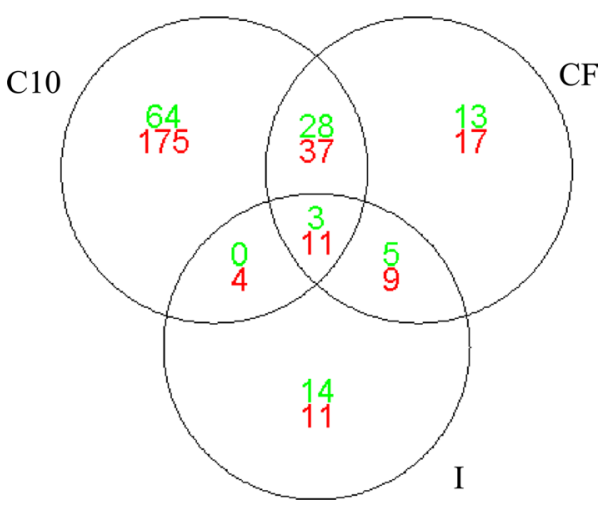

Fig. 1 Differentially expressed genes among all three experimental groups versus REF group are visualized by means of a Venn diagram ( $n=4$ /group). The diagram shows the number of genes that belongs to each of the individual lists, the genes in common between each pair of lists and the genes in common among all three lists (in the center of the representation) for each type of regulation (Green upregulation and Red down-regulation) compared to the REF group

\section{Gene ontology (GO) annotation}

We have considered the most significant GO terms belonging to the biological process (BP), cellular component (CC) 
and molecular function (MF) domains for up- and downregulated genes. Criteria include both the $P$ value together with the counts and the expected counts for each GO term in the $\mathrm{C} 10$ and the $\mathrm{CF}$ groups in comparison with the REF group (Tables S2 and S3, supplementary material). When those GO terms were also commonly enriched by the I diet, the number of the $P$ value together with the counts and the expected counts were also included.

A functional classification, according to the BP with the most significant $(P<0.05)$ terms, was determined for each pairwise comparison (C10 vs REF; CF vs REF; and I vs REF) together for both up- and down-regulated genes as detailed in material and method section (Fig. 2). The first one shows the overrepresented GO terms by the $\mathrm{C} 10$ diet compared to the REF one (Fig. 2a). It revealed 8 functional subgroups which mainly contain down-regulated genes. Among these subgroups, cellular cation homeostasis had the highest number of associated genes followed by digestive system process. All genes related to the regulation of blood pressure terms belonged to cluster 1 (down-regulated
A

\section{GO Term}

Intestinal absorption

Cellular cation homeostasis

Regulation of blood pressure

Brown fat cell differentiation Regulation of inflammatory response

Termination of G-protein coupled receptor signalling pathway

Response to lipid

B

Digestive system process

C

Regulation of digestive system process
Digestive system process

Biological processess

regulation of digestive system process inte stinal absorption digestive system process cytosolic calcium ion transport calcium ion homeostasis cellular calcium ion homeostasis divalent inorganic cation homeostasis cellular divalent inorganic cation... cellular metal ion homeostasis cellular cation homeostasis regulation of ion homeostasis positive regulation of multicellular. regulation of multicellular organismal. regulation of systemic arterial blood.

regulation of angiotensin levels in. regulation of systemic arterial blood. regulation of systemic arterial blood. regulation of angiotensin metabolic. regulation of blood pressure brown fat cell differentiation white fat cell differentiation regulation of inflammatory response termination of G-protein coupled. negative regulation of $\mathrm{G}$-protein. termination of signal transduction positive regulation of GTPase activity cytosolic calcium ion transport cellular response to hydrogen peroxide cellular response to reactive oxygen. cellular response to oxygen levels inte stinal absorption

positive regulation of multicellular cellular response to oxidative stress regulation of multicellular organismal... reactive oxygen species metabolic. digestive system process response to lipid

$\%$ Genes / Term

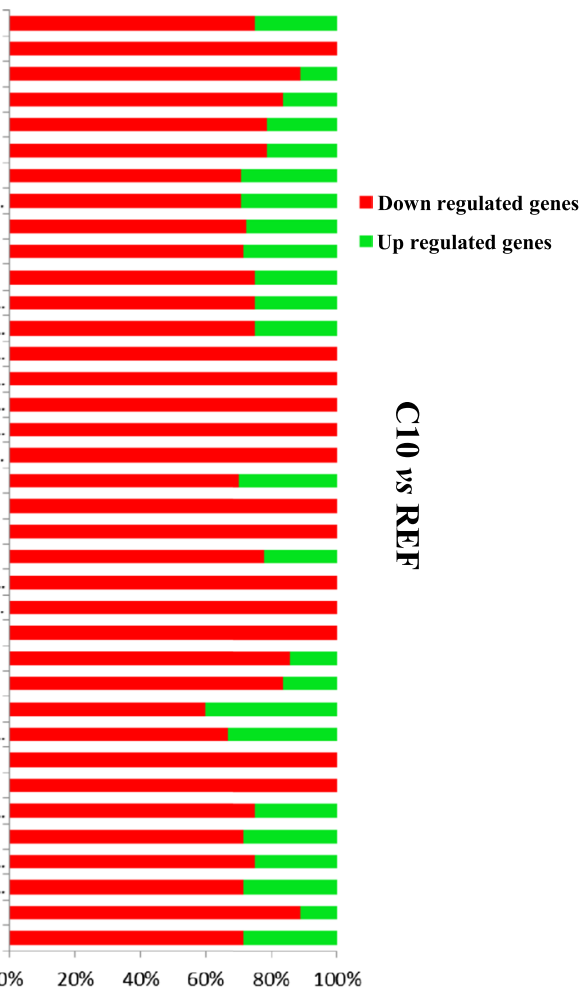

$\begin{array}{llllll}0 \% & 20 \% & 40 \% & 60 \% & 80 \% & 100 \%\end{array}$

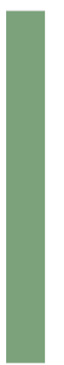

$$
\begin{array}{r}
\text { cholesterol homeostasis } \\
\text { cholesterol transport } \\
\text { sterol homeostasis }
\end{array}
$$

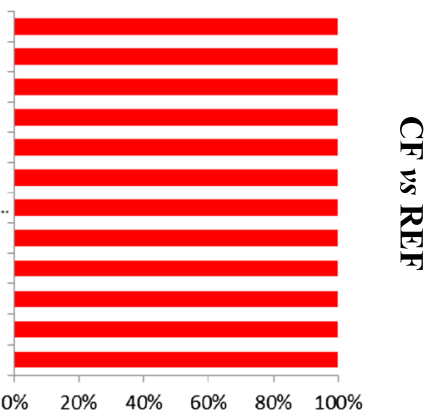

$\begin{array}{llllll}0 \% & 20 \% & 40 \% & 60 \% & 80 \% & 100 \%\end{array}$

regulation of digestive system process

digestive system process

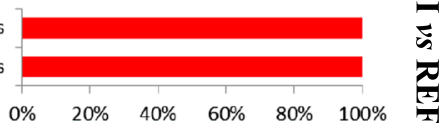

Fig. 2 Common BP belonging to the most significantly overrepresented GO terms for the analyzed clusters. In red are shown the percentages of Cluster 1 (down-regulated) genes associated with the most significant $(P<0.05)$ overrepresented biological process $\mathrm{GO}$ terms and in green the percentages of Cluster 2 (up-regulated) genes associated with these most significant overrepresented biological process GO terms 
genes). The second comparison was between rats fed with the CF diet and those fed with the REF diet (Fig. 2b). When animals were fed the $\mathrm{CF}$, only one functional subgroup (digestive system process) was obtained which only contains down-regulated genes. Similarly, a unique functional category (regulation of digestive system process) containing down-regulated genes appeared when the overrepresented in the up- and down-regulated genes by I diet were compared to the reference group (Fig. 2c).

\section{Analysis of biological processes}

For each one of the comparison discussed above, ClueGO and CluePedia were used to create networks employing all the interactions found between them including the overrepresented BP GO terms in both up- and down-regulated genes (Fig. 3). The network obtained after comparing the $\mathrm{C} 10$ and the REF groups was the one with the highest complexity due to the interactions among the different BP. All these interactions were among overrepresented categories in down-regulated genes (Fig. 3a). The digestive system process had the most significant enrichment, followed by the cellular cation homeostasis term. Moreover, the digestive system process closely related to the intestinal absorption term.

When the CF and REF groups were compared (Fig. 3b), the obtained network revealed that the digestive system process category was the only significant GO biological process obtained. From the considered dataset, all biological processes belonging to this category presented similar significant enrichment. All the obtained interactions were among overrepresented categories in down-regulated genes.

The simplest network was obtained after comparing I and REF groups. It showed that the regulation of digestive system process was the only significant overrepresented category obtained in down-regulated genes.

No significant overrepresented GO terms for up-regulated genes were observed in any comparisons.

\section{Impact of cocoa diet on gene expression}

An extensive number of genes were both up- and down-regulated after the $\mathrm{C} 10$ and CF diets (Table S1, supplementary material). However, given that the main aim of the present study was to elucidate the mechanism by means of which cocoa intake modulates the immune response and the lipid metabolism, the "Results" and "Discussion" sections of the present work are mainly focused in those modulated genes belonging to these two pathways.

The $\geq$ twofold up- and down-regulated genes expression after cocoa diet intake (C10 group) compared to the REF group is shown in Tables 2 and 3, respectively. Likewise, the fold change expression of the same genes by the $\mathrm{CF}$ and
I diets is included. The two genes with the highest fold upregulation after C10 diet were Scgblal and Scnnl $g$ (3.948 and $3.119 \log$ fold change, respectively) (Table 2), the first one encoding a small epithelium-derived protein related to anti-inflammation, and the second one the gamma subunit of a membrane-bound ion channel which plays an essential role in electrolyte (basically sodium transport in kidney, colon, lung and sweat glands) and blood pressure homeostasis. If we consider GO terms, the most up-regulated genes in the C10 group (Scgblal, Cyp2f4, Dpysl4, Fmo2, Hoxd10, Spink3, Angptl4, Padi3, Pde7a, Creg1 and Alas2) (Table 2) belong to the metabolic process (including total, primary and cellular processes, GO:0008152, GO:0044238 and GO:0044237, respectively, in BP domain) and the binding pathways (GO:0005488 in MF domain) terms, respectively. Moreover, the most significantly enriched upregulated GO terms are also represented here. Particularly, Mt2A, Sftpd, Atp12a, Trpv1, Angptl4, Guca2b, Alox15 and Alas2 belong to the response to inorganic substance term (GO:0010035 in BP domain), whereas most of the significantly enriched up-regulated GO terms (GO:0019825, GO:0020037, GO:0046906, GO:0005506, GO:0022892) in the MF domain are represented by the Cyp2f4, LOC287167, LOC689064, Alox15, Alas2, Scnn1 g and Fxyd4.

On the other hand, the most up-regulated genes after $\mathrm{CF}$ and I diet intake were Fxyd4 (a protein-coding gene member of a family of small membrane proteins) and Vom $2 r 3$ (a protein-coding gene involved in $\mathrm{G}$ protein-coupled receptor signaling pathway), respectively. The last gene did not undergo a twofold changed by $10 \%$ cocoa diet (Table S1, supplementary material).

The gene with the highest down-regulation after the C10 group was Tac4 (tachykinin 4), a member of the tachykinin family of neurotransmitter peptides involved in the immune system regulation, which decreased by 2.766 (Table 3). This gene and other genes down-regulated by $10 \%$ cocoa diet are related to the immune system. Some others are the Fcerla ( $\log 2 \mathrm{FC}-1.497)$ encoding the expression of the high-affinity receptor I for IgE Fc fragment for alpha polypeptides, and Ms4a2 $(\log 2 \mathrm{FC}-1.144)$ encoding the same receptor for beta polypeptides. Both genes, together with Tac4, are implicated in pathways related to the mast cell-mediated immunity (GO:0002448), its activation (GO:0045576, GO:0002279, GO:0033008, GO:0033005, GO:0033006, GO:0033003) and its degranulation (GO:0043303, GO:0043304, GO:0043306) in the BP domain. Fcerla and Ms4a2, acting together with Fcgr3a ( $\log 2 \mathrm{FC}-1.230$ ), are also involved in the immunoglobulin binding pathway (GO:0019865 in the MF domain) and, together with Adipoq ( $\log 2 \mathrm{FC}-1.826)$, are involved in cytokine production (GO:0001816 in the BP domain).

In addition, in $\mathrm{C} 10$ group a great number of down-regulated genes, such as Adipoq, Fabpl, Fabp4, Fcerla, Ptgis, 


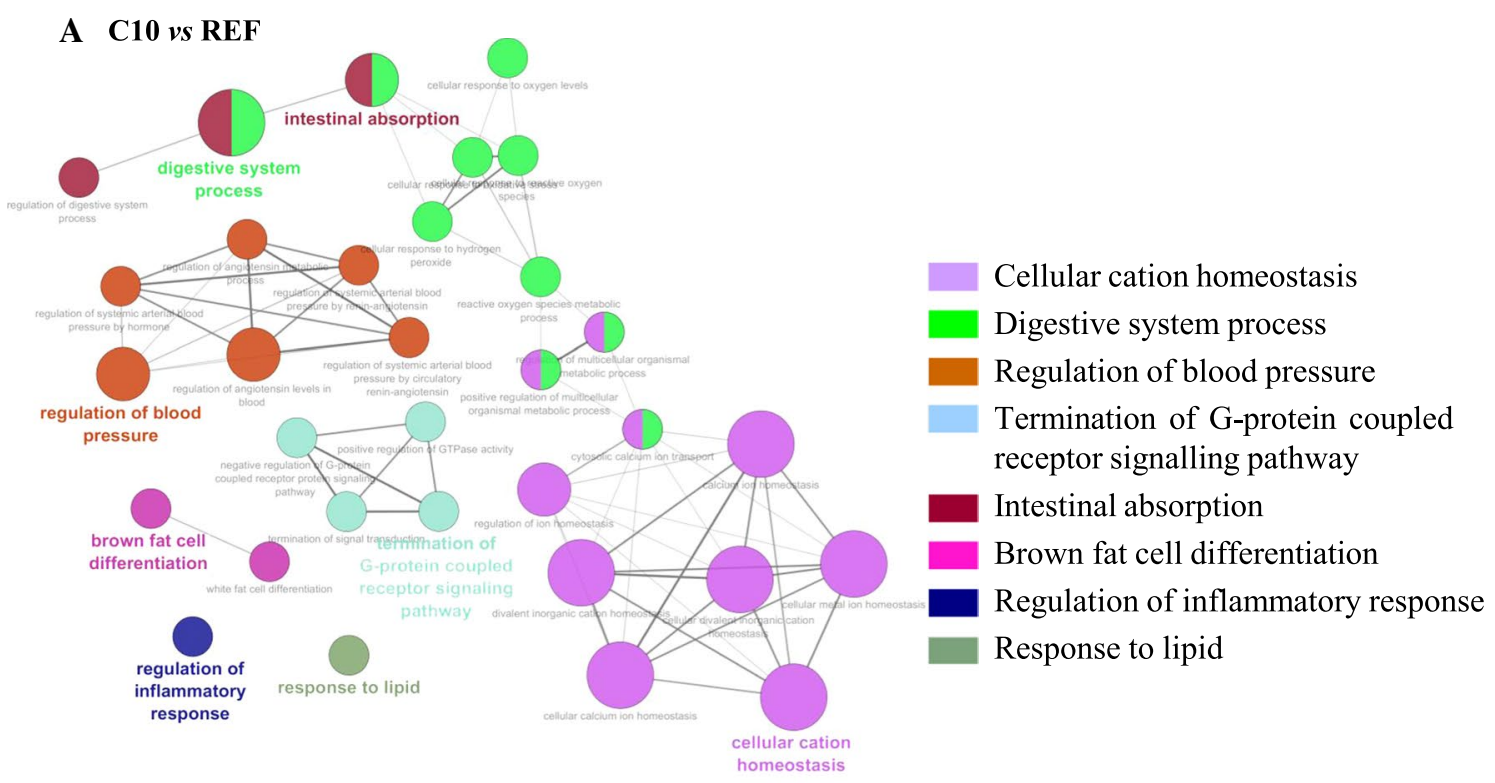

\section{B CF vs REF}

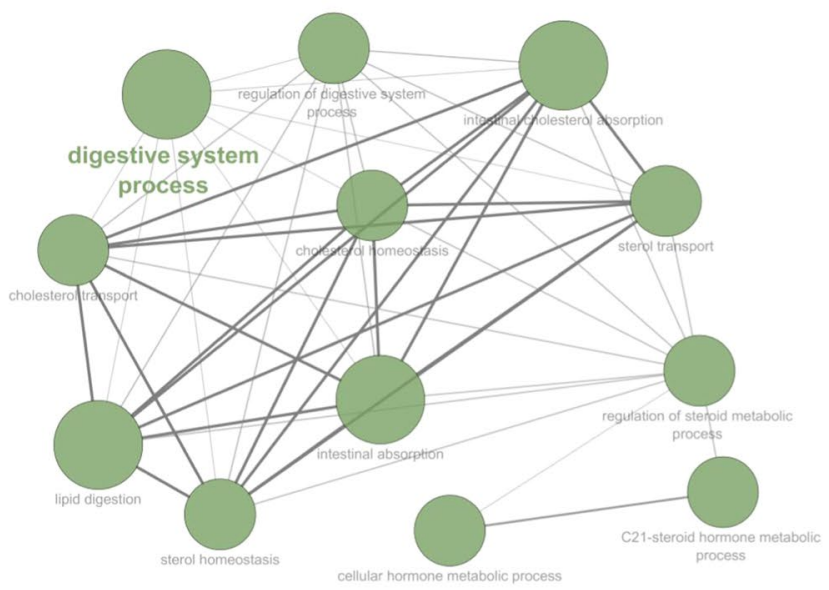

Digestive system process

\section{I vs REF}

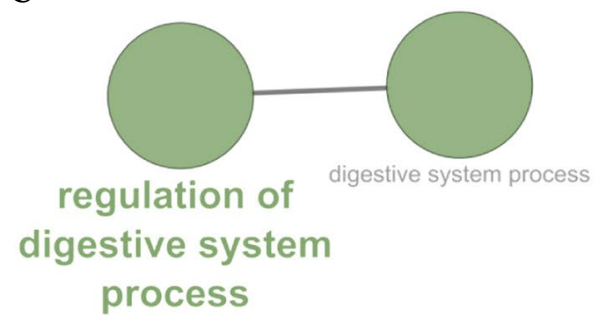

Regulation of digestive system process

Fig. 3 Biological processes network according to ClueGO (only overrepresented categories in down-regulated genes are found). Overrepresented BP GO terms are represented as nodes, and the nodes size represents the term enrichment significance by the Bonferroni

Cyp4f1 and Npc 111, affect the lipid and fatty acid metabolic process pathways (GO:0006629 and GO:0006631 in the BP domain, respectively). Many other genes down-regulated by $10 \%$ cocoa diet are involved in the proteolysis pathway step down method, linked by their Kappa score level $(\geq 0.30)$. Edges represent connections between the nodes and the length of each edge reflects the relatedness of two processes. Only the labels of the most significant terms $(P<0.05)$ are shown

such as Mcpt1, Mcpt2, Mcpt4, Mcpt8, Mcpt10 and Pga5 (GO:0006508 in the BP domain); response to stress such as F2, Cd55, Noxl, Fcerla, Tphl and Tffl (GO:0006950 in the BP domain); plasma membrane such as Tmprss9, 
Fig. 4 Expression of selected genes by real-time PCR. The values are presented as fold change in comparison with the REF group that is considered 1 ( $n=10$ /group). Filled bars represent the expression for each specific gene as determined in the microarray experiments, and empty bars represent the expression for each specific gene as determined by PCR normalized by Gusb. Statistical significance: $* P<0.05$ vs REF group; $\alpha P<0.05$ vs $\mathrm{C} 10$ group
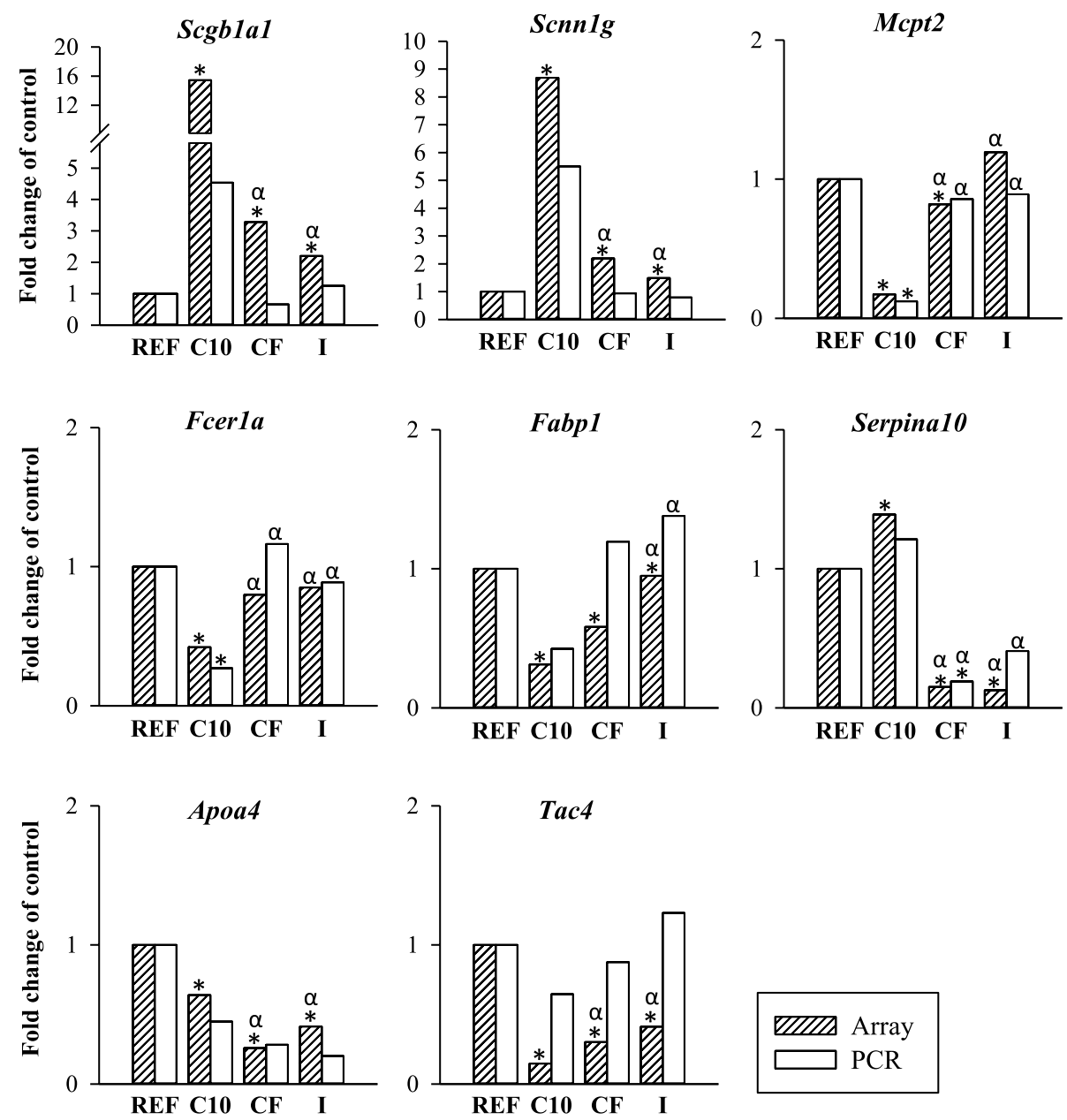

Tnfrsf12a, Casq1, Smpx and Fcgr3a, (GO:0005886 in the CC domain); and protein binding such as Retnlg, Fabp4, Npw, Myl2, and Bhlha15 (GO:0005515 in the MF domain).

Most of these genes highly modified by the cocoa diet were not or were only slightly modified in the CF and I groups with the exception of Rosl (an orphan receptor tyrosine kinase that plays a role in cell differentiation) and Tac4, which were also modified in the CF-fed animals, and Atf3 (activating transcription factor 3) and Retnlb (a cysteine-rich cytokine expressed in the colon and implicated in immunity) in the I-fed animals.

The CF and I diets down-regulated more than twofold the expression of Serpina10 $(\log 2 \mathrm{FC}-2.729$ and -2.987 , respectively), a gene codifying a serpin family member predominantly expressed in the liver and involved in the regulation of the coagulation factors' activity, and Apoa4 ( $\log 2$ FC -1.955 and -1.273 , respectively), a proteincoding gene that plays a role in lipoprotein metabolism (Table S1, supplementary material). On the contrary, these genes were not so affected by $10 \%$ cocoa diet $(\log 2$ FC 0.475 and -0.645 , respectively) (Table $\mathrm{S} 1$, supplementary material).

\section{Validation of microarray results by Real-Time PCR analysis}

Eight genes representative of the affected pathways and with differential expression were selected for further analysis and validation of microarray results using quantitative RT-PCR. The studied genes included Scgblal, Scnnl $g$ (highly up-regulated in the $\mathrm{C} 10$ group), Tac4, Mcpt2, Fcerla and Fabpl (highly down-regulated in the C10 group). In addition, Serpina10 (highly down-regulated in both the CF and I groups) and Apoa4 (highly down-regulated in the $\mathrm{CF}$ group) were also studied.

Results are shown in Fig. 4, where the fold change expression determined both in the microarray and by PCR for each gene in each group is summarized. The quantitative PCR results are consistent with that of microarray. Although not all changes by PCR achieved statistical significance, a similar pattern of expression was determined using both techniques (Fig. 4). The statistical analysis of the real-time PCR results showed that only the expression of Mcpt2 $(P=0.01)$ and Fcerla $(P=0.01)$ was significantly down-regulated in the $\mathrm{C} 10$ group and that the cocoa 
fiber diet produced a significant down-regulation of Serpinal0 expression $(P=0.04)$.

\section{Discussion}

We have previously reported that the intake of a $10 \%$ cocoa diet in young rats induces changes in body weight and in the intestinal environment modulating the gut immune system and microbiota composition [13]. The involvement of cocoa fiber in such effects as well as its precise mechanism of action is unknown to date. In the present study, a microarray of the colon tissue RNA allowed the in-depth study of the modifications of gene expression induced in rats by either a $10 \%$ cocoa diet or two other diets with the same proportion of soluble and insoluble fibers: one based on cocoa fiber and the other containing inulin.

Although the three experimental diets up- or down-regulated a large number of genes, the cocoa intake caused the most pronounced and numerous changes. The $\mathrm{C} 10$ diet was the one which resulted in a higher number of significantly overrepresented GO terms, with most of their genes being down-regulated. Moreover, there were much more interactions between the enriched GO terms after the $\mathrm{C} 10$ diet intake than those obtained after $\mathrm{CF}$ and I diets, with most of these interactions being among down-regulated genes.

A group of genes down-regulated by cocoa intake allowed us to study in-depth the mechanisms of this diet and its involvement in the immune function. In fact, the most down-regulated gene in the C10 group was that of tachykinin 4 (Tac4), which has been described as the promoter of B lineage cells [28]. As B lymphocytes are the immune cells responsible for antibody synthesis, these results could explain previous studies showing the cocoainduced attenuation of immunoglobulin concentration in rats in both the systemic and intestinal compartments [15, $27,29,30]$. This gene modification could also be responsible, at least partially, for the decrease in IgE synthesis in allergic animals induced by the $10 \%$ cocoa diet [10] and even for the same effect reported by other polyphenols [31]. Focusing on allergy, it seems that cocoa intake could also be beneficial in aspects other than IgE synthesis because, as shown here, it down-regulates the expression of genes, such as Fcerla, Ms4a2 and Tac4, involved in several GO terms related to mast cell-mediated immunity, its activation and its degranulation, key events in allergic response. When considering the expression of these immune-related genes in the cocoa fiber and inulin groups, the effects were not so marked, and therefore, this may suggest that polyphenols or other cocoa compounds, but not cocoa fiber, are mainly responsible for the immunomodulatory properties of cocoa by interfering in the B cell ability to produce antibodies and also in the mast cell functionality.
A cocoa diet might also exert its immunomodulatory effects through the down-modulation of the expression of genes involved in cytokine production (Fcerla, Ms4a2 and Adipoq). In addition, cocoa diet in rats has demonstrated certain protective effects against chronic inflammation [32, 33] that could also be related to the down-regulation of the cytokine gene expression and also to the up-regulation of the expression of $S c g b l a l$, the gene that codifies a protein related to anti-inflammation [34]. In this context, both fiber diets-of cocoa and inulin-also increased the Scgblal gene expression, although in a lower intensity compared to that observed in the $\mathrm{C} 10$ group, suggesting that fiber is partially responsible for the anti-inflammatory effect of cocoa but that other cocoa compounds such as flavonoids must also be involved [35]. However, contrary to this suggestion, a significant down-regulation of Scgblal gene expression has been found in a lung tumor mice model treated for 20 weeks with green tea [36].

Another group of genes down-regulated by the $10 \%$ cocoa diet was related to the lipid metabolism. In particular, the expression of Adipoq, an adipocyte-derived hormone involved in glucose and lipid metabolism, and Fabpl, an acid-binding protein found in liver, intestine and kidney involved in fatty acids uptake, transport and metabolism, was decreased by 1.826 and 1.682 FC logarithms. Moreover, the expression of Angptl4, a circulating lipoprotein lipase inhibitor, was up-regulated in the C10 group. Since these genes were less affected by the $\mathrm{CF}$ and I diets, we can suggest that the cocoa diet modifies lipid metabolism and this effect cannot be totally attributed to its fiber content and cocoa flavonoids are probably involved. The results agree with the reported hypolipidemic capacity of a cocoa diet [37-40] as well as in line with the results obtained, here and also in previous studies, on body weight [13, 27, 30, 41, 42]. In fact, the down-regulation of genes related to lipid metabolism has also been described by flavonoids, such as quercetin. The administration of quercetin in mice fed with a high-fat diet reduces the expression of hepatic genes related to lipid and fatty acid production, such as Aldh1b1, Abcg5, Acaca, Fasn, Gpam and Apoa4 [38]. Although some other studies report body weight loss and a reduced fat deposition after polyphenol intake [38, $43,44]$, previous studies carried out in our laboratory using three distinct cocoa materials with different proportions of polyphenols suggest that those effects on body weight cannot be exclusively attributed to cocoa polyphenols but also to other compounds present in cocoa [29]. As in the present study, we evidenced the lack of effect of the CF diet on body weight and on the same genes related to lipid metabolism as the entire cocoa diet, other bioactive compounds of cocoa, such as methylxanthines, could be proposed as being responsible for these effects on lipid metabolism gene expression proteins and body weight. In this context, 
methylxanthines are effective in stimulating resting energy expenditure per se [45] as well as regulating the lipid profile in obese-diabetic rats [46]. In addition, the synergistic interactions between methylxanthines and flavonoids in the thermogenesis have been suggested which could explain their effect on body weight [45].

Regarding cocoa fiber, in spite of the fact that it did not show the effects on the same lipid metabolism genes as cocoa, it is worth noting that the CF diet down-regulated the expression of another gene related to lipoprotein metabolism, the Apoa4. As also validated by RT-PCR, all three experimental diets down-regulated this gene, but the highest effect was observed after CF intake. These results could justify the hypolipidemic effect reported after consumption of either insoluble or soluble CF. In this context, the modulation of serum and liver lipid profile has been reported both in rats fed insoluble CF [18] and those fed soluble CF $[19,20]$. Apoa 4 can also be associated with the response to superoxide and to oxygen radical pathways (GO:0000303 and GO:0000305, respectively); therefore, its down-regulation could elucidate the mechanism by which CF and cocoa flavanols are able to diminish the levels of certain lipid peroxidation biomarkers [39, 47]. From our results, we can also observe the cocoa effects on other genes associated with the antioxidant activity [39]. Thus, a significant increase in the expression of $H b a-a 2$ and $H b b$ genes, encoding alpha and beta betaglobin subunits, respectively, was found in both the $\mathrm{C} 10$ group and the CF group, although the influence was lower than a twofold change.

Another beneficial effect of cocoa intake concerns blood pressure. Cocoa flavanols have been described to possess antihypertensive properties [48], which have made them a subject matter of health claims by the European Food Safety Authority [49]. Possible feasible mechanisms whereby they decrease blood pressure could either be maintaining the endothelium-dependent vasodilatation [50], or inhibiting the angiotensin-converting enzyme (ACE) activity [51]. Partially in line with those mechanisms, in our study, a significant decrease in the expression of Mcpt1 and Mcpt4-both genes involved in the regulation of systemic arterial blood pressure by renin-angiotensin (GO:0003081) — have been observed in $10 \%$ cocoa-fed animals but not in the CF group. Nevertheless, the expression of the Scnnl $g$ gene, involved in blood pressure homeostasis, was up-regulated in the $\mathrm{C} 10$ group and also in the $\mathrm{CF}$ animals, although with a $<$ twofold change. In addition, both the CF diet and the inulin diet down-regulated by more than twofold the expression of Serpina10, a gene involved in the regulation of the coagulation factors' activity, whose deficiency has been related to the risk of thrombosis [52]. Overall, our results show that cocoa intake modifies some colonic genes related to blood pressure regulation, and these effects cannot be attributed to its fiber content.
It remains to be elucidated which component from cocoa, but not cocoa fiber, is the main responsible for these changes in gene expression: both flavonoids and theobromine, present in high proportion in cocoa, are good candidates for such effects.

In summary, this study sheds light on the mechanisms involved in the reported effects of cocoa intake. As shown here, cocoa consumption down-regulates some genes related to the immune system (B cell and mast cell functionality), to lipid metabolism and also to blood pressure in the colon tissue. In addition, after comparing the effects of cocoa in its entirety and those produced by only cocoa fiber, it can be concluded that most of the beneficial effects attributed to cocoa are not only due to its fiber content but that polyphenols and other compounds could also be key factors.

Acknowledgments The present study was supported by a grant from the Spanish Ministry of Economy and Competitivity (AGL201124279). M. M.-C. holds a fellowship from the Generalitat de Catalunya (Grant No. 2014FI_B2 00048). The authors would like to thank the genomic services of the 'Centres Científics i Tecnològics' of the University of Barcelona (CCiT-UB). We also thank Luís Díaz and Diego Amorós from Bioarray S.L. for the microarray procedure and the corresponding analysis, and the Idilia Foods S.L (formerly Nutrexpa S.L.) and InnovaFood 2005 S.L. for providing the conventional cocoa powder and the inulin extract, respectively.

\section{Compliance with ethical standards}

Conflict of interest All authors have no financial disclosures and no conflict of interest.

Open Access This article is distributed under the terms of the Creative Commons Attribution 4.0 International License (http://creativecommons.org/licenses/by/4.0/), which permits unrestricted use, distribution, and reproduction in any medium, provided you give appropriate credit to the original author(s) and the source, provide a link to the Creative Commons license, and indicate if changes were made.

\section{References}

1. Ellam S, Williamson G (2013) Cocoa and human health. Annu Rev Nutr 33:105-128

2. Hooper L, Kay C, Abdelhamid A, Kroon PA, Cohn JS, Rimm EB, Cassidy A (2012) Effects of chocolate, cocoa, and flavan3-ols on cardiovascular health: a systematic review and metaanalysis of randomized trials. Am J Clin Nutr 95:740-751

3. Khan N, Monagas M, Andres-Lacueva C, Casas R, UrpíSardà M, Lamuela-Raventós RM, Estruch R (2012) Regular consumption of cocoa powder with milk increases HDL cholesterol and reduces oxidized LDL levels in subjects at highrisk of cardiovascular disease. Nutr Metab Cardiovasc Dis 22:1046-1053

4. Sarriá B, Mateos R, Sierra-Cinos JL, Goya L, García-Diz L, Bravo L (2012) Hypotensive, hypoglycaemic and antioxidant effects of consuming a cocoa product in moderately hypercholesterolemic humans. Food Funct 3:867-874 
5. Ali F, Ismail A, Kersten S (2014) Molecular mechanisms underlying the potential antiobesity-related diseases effect of cocoa polyphenols. Mol Nutr Food Res 58:33-48

6. Farhat G, Drummond S, Fyfe L, Al-Dujaili EAS (2014) Dark chocolate: an obesity paradox or a culprit for weight gain? Phytother Res 28:791-797

7. Martin MA, Goya L, Ramos S (2013) Potential for preventive effects of cocoa and cocoa polyphenols in cancer. Food Chem Toxicol 56:336-351

8. Smith DF (2013) Benefits of flavanol-rich cocoa-derived products for mental well-being: a review. J Funct Foods 5:10-15

9. Pérez-Cano FJ, Massot-Cladera M, Franch À, Castellote C, Castell M (2013) The effects of cocoa on the immune system. Front Pharmacol 4:71

10. Abril-Gil M, Massot-Cladera M, Pérez-Cano FJ, Castellote C, Franch À, Castell M (2012) A diet enriched with cocoa prevents IgE synthesis in a rat allergy model. Pharmacol Res 65:603-608

11. Etxeberria U, Fernández-Quintela A, Milagro FI, Aguirre L, Martínez JA, Portillo MP (2013) Impact of polyphenols and polyphenol-rich dietary sources on gut microbiota composition. J Agric Food Chem 61:9517-9533

12. Pérez-Cano FJ, Massot-Cladera M, Rodríguez-Lagunas MJ, Castell M (2014) Flavonoids affect host-microbiota crosstalk through TLR modulation. Antioxidants 3:649-670

13. Massot-Cladera M, Pérez-Berezo T, Franch À, Castell M, PérezCano FJ (2012) Cocoa modulatory effect on rat faecal microbiota and colonic crosstalk. Arch Biochem Biophys 527:105-112

14. Pérez-Berezo $\mathrm{T}$, Franch À, Ramos-Romero S, Castellote $\mathrm{C}$, Pérez-Cano FJ, Castell M (2011) Cocoa-enriched diets modulate intestinal and systemic humoral immune response in young adult rats. Mol Nutr Food Res 55(Suppl 1):S56-S66

15. Pérez-Berezo T, Franch À, Castellote C, Castell M, Pérez-Cano FJ (2012) Mechanisms involved in down-regulation of intestinal IgA in rats by high cocoa intake. J Nutr Biochem 23:838-844

16. Hammerstone JF, Lazarus SA, Mitchell AE, Rucker R, Schmitz HH (1999) Identification of procyanidins in cocoa (Theobroma cacao) and chocolate using high-performance liquid chromatography/mass spectrometry. J Agric Food Chem 47:490-496

17. Davy BM, Melby CL (2003) The effect of fiber-rich carbohydrates on features of Syndrome X. J Am Diet Assoc 103:86-96

18. Lecumberri E, Goya L, Mateos R, Alía M, Ramos S, IzquierdoPulido M, Bravo L (2007) A diet rich in dietary fiber from cocoa improves lipid profile and reduces malondialdehyde in hypercholesterolemic rats. Nutrition 23:3323-3341

19. Ramos S, Moulay L, Granado-Serrano AB, Vilanova O, Muguerza B, Goya L, Bravo L (2008) Hypolipidemic effect in cholesterol-fed rats of a soluble fiber-rich product obtained from cocoa husks. J Agric Food Chem 56:6985-6993

20. Sánchez D, Moulay L, Muguerza B, Quiñones M, Miguel M, Aleixandre A (2010) Effect of a soluble cocoa fiber-enriched diet in Zucker fatty rats. J Med Food 13:621-628

21. Chandalia M, Garg A, Lutjohann D, von Bergmann K, Grundy SM, Brinkley LJ (2000) Beneficial effects of high dietary fiber intake in patients with type 2 diabetes mellitus. $\mathrm{N}$ Engl $\mathrm{J}$ Med 342:1392-1398

22. Fernández ML (1995) Distinct mechanisms of plasma LDL lowering by dietary fiber in the guinea pig: specific effects of pectin, guar gum, and psyllium. J Lipid Res 36:2394-2404

23. Roland N, Nugon-Baudon L, Andrieux C, Szylit O (1995) Comparative study of the fermentative characteristics of inulin and different types of fibre in rats inoculated with a human whole faecal flora. Br J Nutr 74:239-249

24. King HC, Sinha AA (2001) Gene expression profile analysis by DNA microarrays. JAMA 286:2280-2288
25. Bindea G, Mlecnik B, Hackl H et al (2009) ClueGO: a cytoscape plug-into decipher functionally grouped gene ontology and pathway annotation networks. Bioinformatics 25:1091-1093

26. Bindea G, Galon J, Mlecnik B (2013) CluePedia Cytoscape plugin: pathway insights using integrated experimental and in silico data. Bioinformatics 29:661-663

27. Ramiro-Puig E, Pérez-Cano FJ, Ramos-Romero S, Pérez-Berezo T, Castellote C, Permanyer J, Franch A, Izquierdo-Pulido M, Castell M (2008) Intestinal immune system of young rats influenced by cocoa-enriched diet. J Nutr Biochem 19:555-565

28. Zhang Y, Lu L, Furlonger C, Wu GE, Paige CJ (2000) Hemokinin is a hematopoietic-specific tachykinin that regulates B lymphopoiesis. Nat Immunol 1:392-397

29. Massot-Cladera M, Abril-Gil M, Torres S, Franch A, Castell M, Pérez-Cano FJ (2014) Impact of cocoa polyphenol extracts on the immune system and microbiota in two strains of young rats. Br J Nutr 112:1944-19544

30. Massot-Cladera M, Franch À, Castellote C, Castell M, PérezCano FJ (2013) Cocoa flavonoid-enriched diet modulates systemic and intestinal immunoglobulin synthesis in adult Lewis rats. Nutrients 5:3272-3286

31. Castell M, Pérez-Cano FJ, Abril-Gil M, Franch À (2014) Flavonoids on allergy. Curr Pharm Des 20:973-987

32. Ramos-Romero S, Pérez-Cano FJ, Pérez-Berezo T, Castellote C, Franch À, Castell M (2012) Effect of a cocoa flavonoidenriched diet on experimental autoimmune arthritis. Br J Nutr 107:523-532

33. Ramos-Romero S, Pérez-Cano FJ, Ramiro-Puig E, Franch À, Castell M (2012) Cocoa intake attenuates oxidative stress associated with rat adjuvant arthritis. Pharmacol Res 66:207-212

34. Mukherjee AB, Kundu GC, Mantile-Selvaggi G, Yuan CJ, Mandal AK, Chattopadhyay S, Zheng F, Pattabiraman N, Zhang Z (1999) Uteroglobin: a novel cytokine? Cell Mol Life Sci 55:771-787

35. Zhang G, Candelaria P, Mäkelä JM, Khoo SK, Hayden MC, von Hertzen L, Laatikainen T, Vartiainen E, Goldblatt J, Haahtela T, LeSouëf NP (2011) Disparity of innate immunity-related gene effects on asthma and allergy on Karelia. Pediatr Allergy Immunol 22:621-630

36. Lu Y, Yao R, Yan Y, Wang Y, Hara Y, Lubet RA, You M (2006) A gene expression signature that can predict green tea exposure and chemopreventive efficacy of lung cancer in mice. Cancer Res 66:1956-1963

37. Jia L, Liu X, Bai YY, Li SH, Sun K, He C, Hui R (2010) Shortterm effect of cocoa product consumption on lipid profile: a meta-analysis of randomized controlled trials. Am J Clin Nutr 92:218-225

38. Jung CH, Cho I, Ahn J, Jeon TI, Ha TY (2013) Quercetin reduces high-fat diet-induced fat accumulation in the liver by regulating lipid metabolism genes. Phytother Res 27:139-143

39. Rimbach G, Melchin M, Moehring J, Wagner AE (2009) Polyphenols from cocoa and vascular health-a critical review. Int J Mol Sci 10:4290-4309

40. Sarriá B, Martínez-López S, Sierra-Cinos JL, García-Diz L, Mateos R, Bravo L (2014) Regular consumption of a cocoa product improves the cardiometabolic profile in healthy and moderately hypercholesterolaemic adults. Br J Nutr 111:122-134

41. Pérez-Berezo T, Ramiro-Puig E, Pérez-Cano FJ, Castellote C, Permanyer J, Franch À, Castell M (2009) Influence of a cocoaenriched diet on specific immune response in ovalbumin-sensitized rats. Mol Nutr Food Res 53:389-397

42. Ramiro-Puig E, Pérez-Cano FJ, Ramírez-Santana C, Castellote C, Izquierdo-Pulido M, Permanyer J, Franch À, Castell M (2007) Spleen lymphocyte function modulated by a cocoa-enriched diet. Clin Exp Immunol 149:535-542 
43. Cherniack EP (2011) Polyphenols: planting the seeds of treatment for the metabolic syndrome. Nutrition 27:617-623

44. Montero M, de la Fuente S, Fonteriz RI, Moreno A, Alvarez J (2014) Effects of long-term feeding of the polyphenols resveratrol and kaempferol in obese mice. PLoS ONE 9:e11282

45. Dulloo AG (2011) The search for compounds that stimulate thermogenesis in obesity management: from pharmaceuticals to functional food ingredients. Obes Rev 12:866-883

46. Jalil AM, Ismail A, Pei CP, Hamid M, Kamaruddin SH (2009) Effects of cocoa extract containing polyphenols and methylxanthines on biochemical parameters of obese-diabetic rats. J Sci Food Agric 89:130-137

47. Kondo K, Hirano R, Matsumoto A, Igarashi O, Itakura H (1996) Inhibition of LDL oxidation by cocoa. Lancet 348:1514

48. Desch S, Schmidt J, Kobler D, Sonnabend M, Eitel I, Saraben M, Rahimi K, Schuler G, Thiele H (2010) Effect of cocoa products on blood pressure: systematic review and meta-analysis. Am J Hypertens 23:97-103

49. European Food Safety Authority (2010) Scientific Opinion on the substantiation of health claims related to cocoa flavanols and protection of lipids from oxidative damage (ID $652,1372,1506,3143$ ), and maintenance of normal blood pressure (ID 1507) pursuant to Article 13 (1) of Regulation (EC) No 1924/2006. EFSA J 8:1792

50. European Food Safety Authority (2012) Scientific Opinion on the substantiation of a health claim related to cocoa flavanols and maintenance of normal endothelium-dependent vasodilation pursuant to Article 13 (5) of Regulation (EC) No 1924/2006. EFSA J 10:2809

51. Actis-Goretta L, Ottaviani JI, Keen CL, Fraga CG (2003) Inhibition of angiotensin converting enzyme (ACE) activity by flavan3-ols and procyanidins. FEBS Lett 555:597-600

52. Corral J, González-Conejero R, Soria JM, González-Porras JR, Pérez-Ceballos E, Lecumberri R, Roldán V, Souto JC, Miñano A, Hernández-Espinosa D, Alberca I, Fontcuberta J, Vicente V (2006) A nonsense polymorphism in the protein Z-dependent protease inhibitor increases the risk for venous thrombosis. Blood 108:177-183 